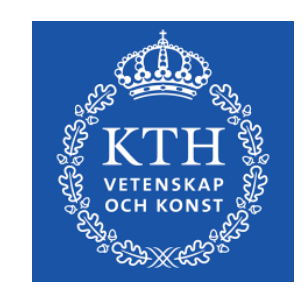

\title{
Magnitude Effects in Lending and Borrowing: Empirical Evidence from a P2P Platform
}

\author{
Wolfgang Breuer, Can K. Soypak, and Bertram Steininger
}

Working Paper 2020:4

Division of Real Estate Economics and Finance Division of Real Estate Business and Financial Systems

Department of Real Estate and Construction Management

School of Architecture and the Built Environment

KTH Royal Institute of Technology 
Magnitude Effects in Lending and Borrowing: Empirical Evidence from a P2P Platform

Wolfgang Breuer and Can K. Soypak

RWTH Aachen University

Department of Finance

Templergraben 64

52056 Aachen, Germany

Email: wolfgang.breuer@bfw.rwth-aachen.de

Bertram Steininger

Royal Institute of Technology

Department of Real Estate and Construction Management

Division of Real Estate Economics and Finance

Stockholm, Sweden

Email: bertram.steininger@abe.kth.se

\section{Abstract}

For varying borrowing and lending amounts, the corresponding subjective discount rates will also vary. A situation where high amounts correspond to lower discount rates is called a conventional magnitude effect, while the opposite is called a reverse magnitude effect. We present an overview of the theoretical arguments for both kinds of magnitude effects. Against this background, we then offer the first comprehensive empirical analysis of this issue based on real-life transaction data. To do so, we rely on more than 9,000 credit applications from the formerly largest German peer-to-peer (P2P) lending platform, Smava, between February 2007 and April 2013. We confirm that there is a conventional magnitude effect for lending money to others but a reverse magnitude effect for borrowing decisions. We suggest, as an explanation for our findings, the prevalence of cost-based determinants of magnitude effects in this special setting.

Keywords: discounting anomalies, magnitude effect, P2P platform, time preferences

JEL Classification D91, G02, G12 


\section{Introduction}

According to traditional economics, intertemporal decision-making is based on exponential discounting of future payments (Samuelson, 1937). However, in real life, violations of exponential discounting are ubiquitous, a situation which leads to a multitude of "discounting anomalies", such as the magnitude effect. In the exponential discounting model, the discount rate applied is independent of the size of the payment to be discounted; however, there is ample theoretical (e.g., Benzion et al., 1989, Benhabib et al., 2010, Read et al., 2013) and empirical (e.g., Chapman, 1996, Green et al., 1997) evidence that discount rates are decreasing functions of the respective payments if those payments are positive. We call this phenomenon the "conventional magnitude effect". Nevertheless, both the theoretical and the empirical evidence is much less conclusive in the case of negative payments.

In fact, there are theoretical reasons why there should be a conventional magnitude effect in this case as well, but there are also potential causes of a reverse magnitude effect, where higher absolute values of negative payments coincide with higher discount rates (for an overview, see Breuer et al., 2019). In a similar vein, experimental evidence for negative outcomes is mixed. While Thaler (1981) propagates findings of a conventional magnitude effect, Hardisty et al. (2013) present results in favor of a reverse magnitude effect. In many cases, however, the outcomes of experimental findings are actually not significant (Baker et al., 2003, Estle et al., 2006, and Mitchell and Wilson, 2010). Empirical evidence from field studies is even scarcer, although laboratory experiments face the problem of being only idealized depictions of realworld decision problems.

Rather interestingly, there are empirical papers on peer-to-peer (P2P) lending where the size of the credit amount is utilized as one control variable (among others) for OLS regressions, with the corresponding interest rate being the dependent variable (see, e.g., Berger and Gleisner, 2009, Pope and Sydnor, 2011, and Lin et al., 2013). In these studies, the regression coefficient for the credit size is typically positive, which hints at the prevalence of a reverse magnitude 
effect. However, in general, scholars working on P2P lending in the field of banking and finance do not seem to be aware of the issue of magnitude effects as illustrated by general decision theory and, therefore, they typically do not discuss this empirical by-product of their studies at all.

We want to close this gap because we deem the sign of the magnitude effect in real-life financial decision problems to be of practical importance. To this end, relying on an analysis of P2P lending instead of examining more professionally organized capital markets (e.g. corporate bond markets) seems, for at least three reasons, to be a natural way to investigate magnitude effects. First, we choose a P2P lending market rather than a corporate bonds market because borrowers and lenders in P2P markets are more likely to be unsophisticated and prone to decision anomalies. In contrast to this, we expect professional decision-makers, such as CFOs and fund managers, to refer more to capital market models like the CAPM. This theory implies, per definition, exponential discounting, and thus less room for behavioral anomalies such as the various kinds of potential magnitude effects. Second, on P2P lending markets, there are at least some non-prevalent agency considerations which stem from the separation of ownership and control and which thus may overlap with behavioral anomalies. Third, according to Longstaff and Schwartz (1995), in corporate bond markets, liquidity aspects may create a negative correlation between the principal amount and the corresponding interest rate. For P2P lending, we can rule out such a liquidity-driven magnitude effect, since there is no correspondingly functioning secondary market. This means that we are able to exclude certain effects originating from overall secondary market conditions and can thus focus more on the determinants of individual decision behavior.

If there is a reverse magnitude effect for negative payments but a conventional one for positive outcomes, then, for example, banks will be able to demand higher interest rates for higher loans granted but will be able to offer lower deposit rates for the higher investments received from their customers. Against this background, we want to contribute to the literature 
on magnitude effects by presenting the first comprehensive empirical study based on real-life transaction data, which focuses primarily on magnitude effects. By doing so, we complement recent experimental findings on this subject.

As outlined at the end of the paper in our discussion section, although lab experiments certainly have their merits, there are also some advantages of relying on real-life market data. In many cases, lab experiments are mostly based on rather small samples of self-selected students as participants who have little experience regarding the decision problems in question. This situation renders the representativeness of the results questionable (see, e.g., Falk and Heckman, 2009, and Charness et al., 2013). Even in cases where the issue of a representative sample is resolved in a satisfactory way, experimental decision situations are typically more or less fictitious. In particular, even if there are monetary consequences of the participants' actions, these will only be in moderate amounts, as the experimenter's budget will not allow too high remunerations. Moreover, it is even more difficult to confront participants with negative monetary consequences of their actions, since one important incentive to take part in experiments is that of earning some money. This is particularly an impediment when investigating magnitude effects for negative outcomes. In addition, and apart from monetary considerations, experimental decision situations are very highly stylized in other ways, for example with respect to maturities. Typically, it will not take years before individuals receive their earnings from participating in an experiment. This is particularly important for experiments aiming for an analysis of intertemporal choices. All of these shortcomings, and possibly some others (such as low numbers of observations in experiments) may affect the conclusions which can be drawn from experiments and lead to a special need for empirical analyses that are based on real-life market data, such as in our study.

Moreover, we extend previous results from studies of P2P lending. In particular, to the best of our knowledge, we present first empirical evidence for P2P lending of a conventional 
magnitude effect for positive payments, i.e. investments. The same is true regarding the empirical examination of non-linearity features of magnitude effects. Following the empirical literature on P2P lending so far, we start with simple OLS regressions without considering the impact of transaction costs. By doing so, we are able to replicate previous similar findings regarding the impact of credit size on interest rates. Nevertheless, even in this setting, we are able to extend the literature, as we allow for quadratic magnitude effects and also consider the relevance of the average investment size on interest rates both separately and in combination with credit size. Moreover, in additional and completely newly designed analyses, we take transaction costs into account and also address the issue of truncated datasets in our regressions by means of Type III Tobit models. These further investigations help us to paint a more differentiated empirical picture. We also contribute to the general decision-theoretical literature on magnitude effects. Our main result is that we can confirm the prevalence of a conventional magnitude effect for positive outcomes (i.e., investments) and we find a reverse magnitude effect for negative outcomes (i.e., loans received).

Our paper is organized as follows. Section 2 presents a brief overview of the theoretical background regarding magnitude effects. In Section 3, we introduce Smava as the P2P lending market that we want to analyze. While we state our hypotheses in Section 4, Section 5 is devoted to our baseline empirical analysis with and without transaction cost consideration. In Section 6, we address the special issue of a possibly truncated dataset and, in Section 7, we discuss our results. Section 8 concludes.

\section{Theoretical Background}

In order to give a brief formal description of magnitude effects, we follow Breuer et al. (2019), which in turn is based on Benzion et al. (1989). To be more precise: let an individual's overall positive or negative outcome at a future point in time $t$ be $\alpha \cdot F$, with $\alpha \geq 1$ being a scale parameter introduced in order to examine potential magnitude effects, while $F>0$ is simply the 
resulting future outcome for $\alpha=1$. In addition, let $P_{\alpha}$ be the subjective present value implied by the future outcome $\alpha \cdot F$, i.e., the present amount of money, which a decision-maker deems to be equivalent to $\alpha \cdot F$. We then may compute a resulting overall rate of return of $\alpha \cdot F / P_{\alpha}-1$ from time 0 to time $t$. The conventional magnitude effect is described by the fact that

$$
F / P_{1}-1>\alpha \cdot F / P_{\alpha}-1 \text { for } \alpha>1
$$

i.e. the individual requires a smaller rate of return for higher values of $F$ when delaying positive payments to the future. In contrast, a reverse magnitude effect would coincide with

$$
F / P_{1}-1<\alpha \cdot F / P_{\alpha}-1 \text { for } \alpha>1 \text {. }
$$

The same definitions apply to situations with negative outcomes, i.e., $F<0$, but then instead of required rates of return, acceptable rates of return for delaying payment obligations to the future are considered.

There are several possible explanations for the prevalence of magnitude effects. According to Breuer et al. (2019), these may be characterized as utility-based or cost-based. Most utility-based approaches, such as that of Loewenstein and Prelec (1992) and Scholten and Read (2010), introduce some kind of utility function $v$, which is used to evaluate future outcomes $\alpha \cdot F$, i.e. $v(\alpha \cdot F)$. Postulating certain (plausible) features of this utility function, one may arrive at a conventional magnitude effect for positive outcomes. At the same time, there is then also a conventional magnitude effect for negative outcomes. A notable exception refers to the approach by Hardisty et al. (2013), which points out the relevance of the present bias for magnitude effects and identifies a conventional magnitude effect for positive outcomes only. In contrast, there is a reverse magnitude effect for negative outcomes.

Another group of approaches is based on cost considerations. The adjustment of a given financial position may incur (mental) adjustment costs (see Benzion et al.,1989, and Benhabib et al., 2010) or give rise to opportunity cost considerations. In these cases, there is again a conventional magnitude effect for positive outcomes but a reverse magnitude effect for negative outcomes. 
In summary, there are several theoretical arguments for a conventional magnitude effect in the case of positive outcomes. Correspondingly, most empirical studies point to a negative relationship between outcome size and discount rates for positive outcomes (for an overview see, e.g., Frederick et al., 2002, and Andersen et al., 2013). In contrast, the theoretical conclusions regarding a magnitude effect for negative outcomes are far less clear. Therefore, in this case, additional empirical analyses seem to be of particular interest. This finding will be reflected in our hypotheses of the next section.

Moreover, it seems intuitively appealing that magnitude effects become weaker for higher (absolute) amounts of positive and negative payments. For example, the relative importance of adjustment costs becomes smaller for higher values of $|F|$. This is also underpinned by some experimental evidence frames (see, e.g., Kirby and Maraković, 1996, and Green et al., 1997) and we will therefore also test this in our empirical section.

\section{P2P Lending Platform Smava: a Brief Characterization}

As outlined in the introductory part of our paper, we choose a P2P lending market rather than a corporate bonds market, because for several reasons this makes it easier to examine behavioral anomalies in decision-making. To be more precise, the real-life market data are taken from the German P2P lending platform Smava.

Founded in 2006 by Alexander Artopé, Eckart Vierkant, and Sebastian Rieschel, Smava became the first German FinTech to offer P2P loans from February 2007 on. Its original purpose had been to act as an online market-place for bringing together potential private borrowers and lenders, such as Zopa in the UK since 2005, or Prosper in the USA since 2006. The annual loan amount mediated by Smava increased from around EUR 1.1m in 2007 to about EUR 13.3m in 2012, totaling about EUR 73.2m. This made Smava undisputedly the largest provider of P2P lending in Germany at that time. In fact, the second most important provider, auxmoney, accounted for a total loan amount of EUR 45m in March 2013. Moreover, in Smava, there were 
19 different loan categories, with Home, Garden, DIY; Debt Restructuring; Working Capital/Investments; and "Others" being by far the most important ones (amounting to an overall share of about $58 \%$ of total financed loans until April 2013) followed by Liquidity; Car and Motorcycle; Business Expansion; and Commercial Loans (additional 31\%).

A loan application in Smava starts with a potential borrower submitting a loan request for a certain loan category (e.g. Debt Restructuring) and a certain amount ranging from EUR 250 to EUR 50,000 with a non-negotiable interest rate. Subsequently, all members of the credit platform are notified and can decide whether and how much they want to contribute to this project (from EUR 250 up to at most EUR 10,000 for all investments of one individual lender). Due to the rules of German banking regulations, it is actually the Fidor Bank (as the official partner of Smava) that grants loans to applicants and then sells them to the private lenders according to the latter's shares in the whole loan amount.

Since 2012, Smava has expanded its business model from being a purely P2P platform to being a website that compares credit terms of traditional financial institutions and arranges loans between traditional banks and private borrowers besides the original P2P lending. This development was accompanied by strategic investments of existing and new private-equity investors, such as Ventures, Earlybird, and Neuhaus Partners. The former P2P platform became mainly a credit comparison portal during 2013-2014. The focus of P2P is now on brokering loans from traditional banks. Therefore, for our analysis, we rely on their mostly purely P2P period of February 2007 to April 2013.

\section{Hypotheses}

According to our description of the loan application process in the previous section, for both borrowers and lenders the decision problem is thus primarily framed in interest rates ("interest rate frame", henceforth) and not in annuity payments ("money frame", henceforth). Lenders are recommended to base their decision on a return calculator, into which they have to enter the investment amount and its maturity as well as the corresponding nominal interest rate and 
the borrower's rating. Then, the return calculator computes the corresponding "expected rate of return" and recommends this as the base for investors' decision-making. On the borrowing side, borrowers themselves set the nominal interest rate which they want to pay when applying for a credit. Thus, they obviously have to think in interest rate terms, too. Moreover, as required by German law, Smava computes the annual percentage rate (APR) for each credit, including transaction costs and fees. We will return to the distinction between interest rate frames and money frames later on, when we discuss our empirical findings.

However, our analyzed dependent variable is not the interest rate stated by the respective potential borrower, but the resulting credit spread (Credit Spread henceforth, defined according to Table 1). The Credit Spread is the nominal interest rate of the loan (Interest Rate in Table 1) minus the rate of return for (almost risk-free) German government bonds with the respective maturity (i.e. minus Risk-free Rate Dependent on Maturity as defined in Table 1). Due to the time-varying, but exogenous yields of German government bonds, the Credit Spread is the relevant interest rate (component) for borrowers, and therefore for our study. Think of two different points in time, $t_{1}$ and $t_{2}$, with the only difference between them being a different risk-free interest rate for a given maturity. Then, for a borrower's given creditworthiness, we would expect different required interest rates for a given loan application at times $t_{1}$ and $t_{2}$, which mirrors the difference in prevailing risk-free interest rates at these two points in time. By concentrating on Credit Spread, we are able to eliminate this confounding effect. Nevertheless, our later empirical results are very similar even though we rely on nominal interest rates.

Later, we also extend our analysis by incorporating transaction costs for borrowers and for lenders' expected returns. In general, we regress these spreads on credit size, the creditors' average investment amount, and other control variables in our empirical analysis. Against the background of our theoretical overview, we formulate the following hypotheses:

HA: Credit spreads are decreasing (at a decreasing rate) with creditors' average investment amount. 
HB1: Credit spreads are decreasing (at a decreasing rate) with credit size. versus

\section{HB2: Credit spreads are increasing (at a decreasing rate) with credit size.}

Theoretical conclusions seem to be unambiguous regarding the magnitude effect in the domain of positive outcomes. However, for situations with negative outcomes, both a conventional and a reverse magnitude effect may be possible. Therefore, we formulate two contradicting hypotheses, HB1 and HB2, and have to settle the matter empirically. The finding according to HB1 and HB2 will also help us to identify the relative importance of utility-based and cost-based theories for explaining magnitude effects, since HB1 is largely in line with the former theories, while the latter theories correspond to HB2.

Strictly speaking, Hypotheses HA and HB1/HB2 only hold true if there are no other future payment consequences. However, it seems plausible to assume that individuals form different mental accounts for different future payoffs and therefore evaluate the consequences of both borrowing and lending decisions mainly independently of their other payment consequences. Exactly such an assumption typically underlies any kind of experimental setting, because other positive or negative payments for individuals are normally not controlled for.

$$
\text { >> Insert Table } 1 \text { here. }<<<
$$

\section{Baseline Empirical Analysis}

\subsection{Data}

Using a web crawler, we have extracted credit data (annual interest rates, fee, credit size, average investment amount per creditor, maturity, risk indicators, age, and sex) from the formerly largest German P2P lending platform, Smava. The data cover more than 9,000 credit applications submitted between February 2007 and April 2013, so that we can focus on the company's purely P2P period. All variables are defined in Table 1 and the corresponding descriptive statistics are presented in Table 2. 
On average, a borrower has to pay a Credit Spread of $6.9 \%$ resulting from a nominal Interest Rate of $8.9 \%$ and a Risk-free Rate Dependent on Maturity of $2.0 \%$. An application has on average a Credit Size of EUR 8,230 (median: EUR 5,500) and a Maturity of 60 months (67\% of all cases). A lender grants on average (Average Investment Size) a loan of EUR 470 (median: EUR 420). The two highest creditworthiness ratings (Schufa Rating) of a borrower based on their past payments are A (best) and B (second-best) and sum up to $40 \%$ of all applications. For the future debt service capacity of a borrower ( $K D F$ Indicator), the category with the highest probability is 3 (second-worst) with $38 \%$. Both of the ratings - Schufa and KDF Indicator - are explained in more detail in the following subsection. Furthermore, an applicant is on average 46 years old (according to Age) and typically male (in only $27 \%$ of all cases are applicants Female). Most borrowers are raising a loan for the first time (only 35\% of the cases are taken out by a Repeat Borrower). Over the years, P2P lending grew from 3\% of all events in our sample in 2007 to $29 \%$ in 2010 and subsequently fell to $19 \%$ in 2011 and $15 \%$ in 2012 (Year).

$$
\text { >> Insert Table } 2 \text { here. }<<<
$$

\subsection{Controlling for Risk Considerations}

The credit spread may be determined not only by the magnitude effect but also by risk considerations. We therefore have to apply several control variables in order to isolate the pure magnitude effect, and we have to be wary of risk features as a source of a potential relationship between credit size or average investment amount on the one hand and credit spread on the other. First of all, for a given borrower with fixed credit size, the probability of default or the expected recovery rate of a loan (i.e. the percentage of debt that can be repaid) in the case of insolvency will not be a function of the average investment amount. However, higher average investment amounts may indicate less diversification on the lenders' side, supporting ceteris paribus a positive relationship between the average investment amount and the required credit spread. Thus, if any effect, then this particular one will potentially make it even harder for us to confirm Hypothesis HA. 
In contrast, higher credit amounts may indeed affect the probability of default or the expected recovery rate of a loan in the case of insolvency, and the credit spread is positively related to the probability of default and negatively to the recovery rate (Merton, 1974, and Cox and Ross, 1976). Therefore, it is necessary to control for these two risk characteristics. However, neither of these risk features is directly observable. Instead, lenders have to rely on the borrower's Schufa Rating and the KDF Indicator as risk indicators which are shown to predict the funding and default probability (Dorfleitner et al., 2016). Both the Schufa Rating and the $K D F$ Indicator of the applicant are available to lenders for each credit application. Schufa is a German rating company that assesses the creditworthiness of a certain individual based on comprehensive historical records including, e.g., current accounts, credit card debts, and smartphone contracts. Each individual is assigned to a category between $A$ (best) and $H$ (worst). The rationale of these scores is comparable with the FICO Score in the US or Experian, Equifax, and TransUnion in the UK. Similarly, Smava itself calculates a borrower's debt service capacity (in German: Kapitaldienstfähigkeit $-K D F$ ), transforms the measurement based on all existing payment obligations, including the desired new credit amount, and assigns each borrower a specific grade between 1 (best) and 4 (worst). Apparently, this KDF indicator is a direct function of the desired credit size and thus able to capture the influence of the credit size on a borrower's creditworthiness. For both rating systems, we use the "least creditworthy" category as the reference point. In Table 3, we test the linear combination characteristic of the two different credit score systems (Schufa Rating and KDF Indicator) with pairwise Spearman's rank correlation coefficients. The results show that even in those cases where coefficients are statistically significantly different from zero, their magnitudes are far too low to suggest a highly linear relationship; therefore, the historical creditworthiness measurement (Schufa Rating) and Smava's proprietary measure for a borrower's debt service capacity (KDF Indicator) are two linearly independent variables. This result is supported by a very low value of 0.05 for Cramér's $\mathrm{V}$. 
We also account for general financial market features that may be relevant for bankruptcy risk or for the expected recovery rate. To be more specific, we control for the risk-free interest rate in our empirical analysis by including the rate of return for German government bonds with a 10-year maturity (Risk-free Rate (10 Ys Treasury Yield) in Table 1) of the previous month before the credit application was made. Following Collin-Dufresne et al. (2001), we add Yield Curve (10-2 Years), i.e., the difference between the rate of return of the 10-year and the 2-year government bond. These data are obtained by the respective sub-index of the German bond index (REX). The monthly return of the German stock market index DAX (Stock Market Returns $(D A X))$ is our proxy for the general market sentiment, and we calculate the total return of the preceding month before the credit application was made. All capital market data are obtained from Thomson Reuters Datastream. Moreover, we control for a loan's maturity and borrowers' age (Age) and gender (Female). The descriptive statistics for these control variables are also given in Table 2. In Table 4, we show the pairwise Bravais-Pearson correlation coefficients among these additional explanatory variables. With absolute values of 0.32 and below, no significant correlation coefficient indicates a multicollinearity issue between variables. The only exemption is the correlation $(-0.96)$ between the maturity of 36 months and 60 months, since these two possibilities were the only possible alternatives before October 2012 .

$$
\text { >> Insert Table } 4 \text { here. }<<<
$$

\subsection{Ordinary Least Squares Results}

To test our Hypotheses HA and HB1/HB2, we divide our research design into three slightly different structural models. First, we analyze the relationship of Credit Size $\left(C_{i}\right)$ and other control variables (CONTROLS) to Credit Spread $\left(S_{i}\right)$ and its square from the perspective of a borrower (Borrowing Model). In the second model (Investment Model), we switch to a lender's perspective and analyze the impact of Average Investment Size $\left(I_{i}\right)$ and its square on Credit Spread. Finally, we combine both models (Combined Model). In Section 6, we verify 
our ordinary least squares (OLS) results by using advanced regression models to address potential observation limitations for the dependent variables.

\subsubsection{Results without Transaction Costs}

In a first step, we neglect a potential impact of transaction costs for borrowers as well as for lenders and we regress Credit Spread on different explaining factors by using a simple OLS regression model (see Equations (3)-(5) for the Borrowing Model, the Investment Model, and the Combined Model; variables printed in bold type are vectors).

$$
\begin{gathered}
S_{i}=\alpha+\beta_{1} \cdot C_{i}+\beta_{2} \cdot C_{i}^{2}+\boldsymbol{\delta} \cdot \text { CONTROL }_{i}+\varepsilon_{i}, \\
S_{i}=\alpha+\gamma_{1} \cdot I_{i}+\gamma_{2} \cdot I_{i}^{2}+\boldsymbol{\delta} \cdot \text { CONTROL }_{i}+\varepsilon_{i}, \\
S_{i}=\alpha+\beta_{1} \cdot C_{i}+\beta_{2} \cdot C_{i}^{2}+\gamma_{1} \cdot I_{i}+\gamma_{2} \cdot I_{i}^{2}+\boldsymbol{\delta} \cdot \text { CONTROLS }_{i}+\varepsilon_{i} .
\end{gathered}
$$

The coefficient $\alpha$ stands for a model's intercept, and the $\beta$ 's as well the $\gamma$ 's for the most relevant sensitivities regarding Credit Size $\left(C_{i}\right)$ and Average Investment Size $\left(I_{i}\right)$ in EUR 1,000 in their base and squared form. The latter is necessary to account for the hypothesized nonlinear relation between credit spreads on the one hand and credit size or investment size on the other, respectively. The vector $\boldsymbol{\delta}$ summarizes the different sensitivities with respect to various control variables (Risk-free Rate (10 Ys Treasury Yield), Yield Curve (10-2 Years), Stock Market Returns (DAX), Schufa Rating, KDF, Maturity, Repeat Borrower, Age, Female, and Year). The individual observations are captured by $i$ and their standard errors in $\varepsilon_{i}$.

In Table 5, we present the OLS results for our three different models (Borrowing Model, Investment Model, and Combined Model). In the OLS setting, the Borrowing Model (Model (1) in Table 5) shows that Credit Size does indeed have a positive and significant impact (0.0377) on Credit Spread for a borrower. Regarding Credit Size Squared (square of the credit size), we find a significantly negative impact $(-0.0005)$. From the perspective of a lender (Investment Model, Model (2) in Table 5), we see that that Average Investment Size has a negative $(-0.3163)$ and Average Investment Size Squared (square of the investment size) a positive but insignificant impact (0.0160) on Return Spread. For the joint perspective (according to the 
Combined Model, Model (3) in Table 5), we include all four size parameters (Credit Size, Credit Size Squared, Average Investment Size, and Average Investment Size Squared), simultaneously confirming our previous results. Credit Size has a positive and significant impact (0.0400) and Average Investment Size a negative impact $(-0.4383)$. The squared terms indicate a decreasing slope for both size factors $(-0.0005$ and 0.0328$)$. All four size parameters are statistically significant at least at a level of 5\% and, in general, all three models are able to explain around $74 \%$ of the variation of the Credit Spreads. In summary, the results of Table 5 are in line with Hypothesis HB2, which says that Credit Spreads are increasing (at a decreasing rate) with Credit Size. They are also in accordance with Hypothesis HA, which indicates that Credit Spreads are decreasing (at a decreasing rate) with creditors' average investment amount. In the latter case, however, the postulated non-linearity of the magnitude effects seems to be less pronounced than in the former case.

Note that for the combined model, we treat our sample as though it consists of 9,133 observations regarding the impact of credit size and an additional 9,133 observations addressing the relevance of average investment size. We do so to ensure comparability to our regression results of the following subsection, where we explicitly account for transaction costs leading to different values of credit spreads and return spreads for the same credit application. Nevertheless, due to our clustering according to borrower ID, the results of Model (3) in Table 5 are completely identical if we treat our sample as a collection of (only) 9,133 combined observations of credit applications and corresponding credit sizes as well as average investment magnitudes.

$$
\text { >> Insert Table } 5 \text { here. }<<<
$$

Based on the results of the Combined Model, a median borrower pays EUR 149.55 additional interest over the median maturity ( 5 years) for a standard deviation increase in Credit Size. Therefore, the additional interest payment per year is EUR 29.91. The respective value for a mean borrower is EUR 163.99 with an additional interest payment of EUR 32.80 per year. 
An overview of these values is given in Table 6 . These values are economically significant for all four size parameters in each model. Our findings imply that even in real-life decision situations, the reverse magnitude effect is not only statistically significant (Table 5) but also economically meaningful (Table 6).

The corresponding figures for the conventional magnitude effect are notably smaller (Table 6). A median lender forgoes EUR 3.32 additional interest over the median maturity (5 years) for a standard deviation increase in Average Investment Size. Therefore, the reduction in interest payment per year is EUR 0.66. The respective figures for a mean lender are around the same. On the one hand, these values are not as small as they might appear at first sight. Suitable reference values may be the average value which lenders invest (Average Investment Size: EUR 470 ) and the average credit amount which a borrower raises (Credit Size: EUR 8,230; see Table 2). By using these figures, the relative discounts/premiums are $1.8 \%(150 / 8,230)$ and $0.7 \%$ (3.32/470). On the other hand, our findings on the conventional magnitude effect are complements to those of Andersen et al. (2013), who (for the case of positive payments) point out that the conventional magnitude effect in their field experiment is statistically significant but comparatively small in economic terms. Both these aspects of the conventional magnitude effect (statistically significant (Table 5) but economically small (Table 6)) apply for our P2P dataset with high actual (positive) payments as well and, consequently, not only for lab or field experiments with rather small actual payments.

$$
\text { >> Insert Table } 6 \text { here. }<<<
$$

We abstain from discussing the signs of the coefficients of our control variables in detail. Nevertheless, the reader might wonder why maturity has a significantly negative impact on the credit spread. Although we are not aware of any paper studying P2P lending platforms and addressing this issue, we may refer to the corporate bond literature. According to Chen et al. (2007), yield spreads generally increase (decrease) with maturity for investment (speculative) grade bonds (see also Merton, 1974, and Helwege and Turner, 1999). Interpreting borrowing 
via a $\mathrm{P} 2 \mathrm{P}$ lending platform as an action that is predominantly of interest to borrowers with below-average creditworthiness (recall that debt restructuring is by far the most important reason for referring as a borrower to Smava), the analogy to speculative-grade bonds may explain our findings.

Moreover, it seems worth to be mentioned that our results regarding our hypotheses remain almost completely unchanged if we use the original borrowing Interest Rate for each realized loan application instead of only the Credit Spread as dependent variable, although in the former case, the confounding influence of changes in market interest rates over time is only imperfectly controlled for.

\subsubsection{Results with Transaction Costs}

Now, we take the most important transaction costs faced by borrowers and lenders into account to underpin the practical relevance of our results in the previous section. In doing so, we refine Equations (3) to (5).

For the borrower's perspective (Equation (3') below), we subtract the corresponding transaction cost $\left(F e e\left(F_{i}\right)\right.$ as a debt discount in euros; see Table 1$)$, which is a certain percentage share of Credit Size $C_{i}$ depending on the respective Maturity and the transaction date (fee scheme changed during observation period) and has to be paid by the borrower from Credit Size to Smava at the time of obtaining the credit. This results in a new size factor $C_{i}-F_{i}$ (Credit Size-Fee).

For the investment perspective (Equation (4') below), we use a special return figure that is computed by Smava for potential investors and recommended as the relevant decision variable on a special sub-page on the website of each project description and referred to as (somewhat imprecisely) "Expected Return" (see also Table 1). For this return figure, the investorspecific transaction costs (risk surcharge and lender's fee) are subtracted from the nominal interest rate. The risk surcharge is, in particular, a function of the borrower's credit rating and the maturity of a loan and is calculated by Smava as a kind of insurance premium to mitigate a 
creditor's risk against losing her or his principal. To calculate the investor-specific Return Spread $\left(R S_{i}\right)$ after transaction costs, the counterpart to Credit Spread $\left(S_{i}\right)$ in the Borrowing Model, we subtract the rate of return for government bonds with the respective maturity, too.

Once again, we integrate both previous approaches in a Combined Model (Equation ( $5^{\prime}$ ) below) to determine simultaneously the effect of Credit Size-Fee, $C_{i}-F_{i}$, on Credit Spread $S_{i}$ (Borrowing Model) and Average Investment Size $I_{i}$ on Return Spread $R S_{i}$ (Investment Model). In this model, the dependent variable $(R) S_{i}$ (Credit Spread or Return Spread) is specific for the explaining factor set (Credit Size-Fee or Average Investment Size). Furthermore, we control for the investment dataset by adding a dummy variable to the investment subsample $\left(D_{\text {Inv }}\right)$. The respective coefficient $(\theta)$ controls for a systematic difference between the investment subsample and the borrowing subsample in the Combined Model, as our independent variable differs in both cases. It should be mentioned that such a dummy variable is not necessary for the corresponding Model (3) of Table 5 due to the absence of transaction costs. As a consequence, adding this dummy variable to Model (3) of Table 5 would leave all regression coefficients unaffected.

$$
\begin{aligned}
& S_{i}=\alpha+\beta_{1} \cdot\left(C_{i}-F_{i}\right)+\beta_{2} \cdot\left(C_{i}-F_{i}\right)^{2}+\boldsymbol{\delta} \cdot \text { CONTROLS }_{i}+\varepsilon_{i}, \\
& R S_{i}=\alpha+\gamma_{1} \cdot I_{i}+\gamma_{2} \cdot I_{i}^{2}+\boldsymbol{\delta} \cdot \boldsymbol{C O N T R O L S} \boldsymbol{S}_{i}+\varepsilon_{i}, \\
& \text { (R) } S_{i}=\alpha+\beta_{1} \cdot\left(C_{i}-F_{i}\right)+\beta_{2} \cdot\left(C_{i}-F_{i}\right)^{2}+\gamma_{1} \cdot I_{i}+\gamma_{2} \cdot I_{i}^{2}+\boldsymbol{\delta} \cdot \boldsymbol{C O N T R O L S} \boldsymbol{S}_{\boldsymbol{i}}+\theta \cdot D_{I n v}+\varepsilon_{i} \text {. }
\end{aligned}
$$

So far, we have adhered to an OLS regression model and we have checked whether and to what extent transaction costs change the impact of size parameters on Credit Spread and Return Spread. The results are shown in Table 7. We expect that for all three transaction costscorrected models, the results will be close to the corresponding models of Table 5, since the transaction costs result from constant shares of Credit Size or Average Investment Size. Therefore, they should be theoretically irrelevant for the magnitude effects regardless of how they 
are taken into account. Moreover, owing to mental accounting, individuals may make their borrowing or lending decision based on gross values, and they evaluate transaction costs separately so that any kind of magnitude effect is not affected by these kinds of transaction costs.

Indeed, results for the coefficients of Table 7 are almost identical to those of Table 5. In the Borrowing Model (Model (4)), the coefficient of Credit Size-Fee is 0.0388 (without transaction costs: 0.0377). The coefficient for the non-linear effect of Credit Size-Fee amounts to 0.0005 and is thus the same as in Table 5. In the Investment Model (Model (5)), Average Investment Size influences Return Spread negatively with -0.2880 (without transaction costs: -0.3163 ). The squared term amounts to 0.0131 (without transaction costs: 0.0160 ) but is statistically insignificant at conventional levels. In the Combined Model (Model (6)) with all four size parameters (Credit Size-Fee, Credit Size-Fee Squared, Average Investment Size, and Average Investment Size Squared), all coefficients are also about the same as in the model without transaction costs and statistically significant at least at a level of 5\%. The investment dataset dummy (Investment Sample) reduces the spread by 3.1 percentage points, which is statistically significant at the $0.1 \%$ level. This decline is mainly driven by the "default insurance" payment of the lenders.

We do not see any systematic change in the direction or magnitude of the coefficients for our four size variables or for the control variables, either. The adjusted $R^{2}$ decreases from the Borrowing Model with $74 \%$ to $26 \%$ in the Investment Model and from $75 \%$ to $61 \%$ in the Combined Model. This means that the size and control variables are less suitable for explaining Return Spreads in a separate model. For this reason, we stay with the Combined Model for the rest of this paper, although our results in the next section would be similar if they were based on the Borrowing or the Investment Model.

Our finding that both kinds of magnitude effects are not affected by transaction costs may also support our view presented at the end of Section 4 regarding the general relevance of mental accounting. If mental accounting might be relevant for the specific issue of transaction 
costs, it is certainly going to be relevant for the general issue of single positive or negative outcomes from lending and borrowing decisions, as well.

$$
\text { >>> Insert Table } 7 \text { here. }<<<
$$

\section{Robustness Check for Limited Dependent Variables}

Besides the problem of transaction costs, our dependent variables (Credit Spread and Return Spread) may suffer from a limited distribution feature - a truncation. Therefore, a special regression model addressing this limitation might be more appropriate than an OLS approach in order to analyze our dataset.

\subsection{General Characterization of Truncation}

In the case of a truncation of our dataset, it would not be possible to observe a specific range of values of explanatory variables for borrowers and lenders, because these (mostly due to the lenders) are not willing to close a deal with spreads under a specific threshold (e.g. negative spreads might not be accepted). In other words, we only observe a restricted range of explanatory variables due to a restriction of the dependent variable. This is contrary to a censored dataset, where we would observe the full range of all explanatory variables but only see a restricted range of the dependent variable. Therefore, only a subset of the theoretical full dataset is available for our analysis. Furthermore, this truncation would be incidental - it is based on the participants' and not the surveyor's decision. Following the classification by Amemiya (1985), a Type III Tobit model can help to analyze the spreads. This model, also known as a Truncated Normal Hurdle (TNH), separates the participation decision (in our case: the decision to enter into a P2P contract) from the amount decision (in our case: the magnitude of Credit Spread or Return Spread) (see Wooldridge, 2010, p. 815).

\subsection{Theoretical Reasons for Truncation}

According to the potential limitation issue, we take a closer look at the general price determination in the credit market and the approach for calculating our dependent variables. As 
already pointed out, we define Credit Spread as the difference between the stated nominal interest rate and the yield of a German government bond index with a corresponding maturity. Both subtraction components could exhibit a potential truncation at the value of zero for a period of macroeconomic stability. In addition, lenders should only be willing to invest their money in the risky $\mathrm{P} 2 \mathrm{P}$ market if they receive a higher interest rate than for an almost risk-free German government bond yield. Consequently, the Credit Spread, as the difference between the two interest rates, should be at least zero. Furthermore, the riskless bond yield itself should be higher than zero; otherwise institutional investors would not be willing to invest in governmental bonds. However, we have observed negative governmental bond yields in the aftermath of the eurozone sovereign debt crisis (e.g. for the German 3-year bonds after August 2014). Moreover, private lenders might be unaware of the current risk-free rate (the exact value or even the concept), so that their demanded interest rate might also be lower than the risk-free rate, resulting in negative Credit Spreads. The same applies for the second dependent variable, Return Spread, and its components: Expected Return and the yield of a maturity of a corresponding German government bond index - the same subtrahend as for Credit Spread. The theoretical existence of negative Credit Spreads and Return Spreads may indicate a truncated dataset, where negative spreads are possible but most lenders are not willing to accept such spreads lower than zero. In order to check such a behavior, we re-examine the descriptive statistics.

\subsection{Descriptive Statistics for Credit Spread and Return Spread Reconsidered}

In our descriptive statistics, we observe a minimum value of $-1.67 \%$ for Credit Spread (see Table 2), but in total, we have only four cases out of 9,133 observations with a negative Credit Spread in our dataset. For Return Spread, the smallest value is $-6.26 \%$ and 208 of all 9,133 observations are, in total, negative. In the next step, we analyze the probability density function (pdf) of the spreads. As we can derive from Figure 1 and Table 8, the dependent variable Credit Spread is right-skewed with a Pearson's moment coefficient of skewness of 0.74 
that is statistically significant at the $0.1 \%$ level. The values pile up at a range of $4 \%$ to $6 \%$, but the pdf shows a mesokurtic distribution. The second dependent variable Return Spread is significantly leptokurtic with a kurtosis coefficient of 5.02 but not skewed at any conventional significance level. These values and the corresponding significance tests are shown in Table 8 .

$$
\text { >> > Insert Table } 8 \text { here. }<<<
$$

In Figure 1, the histogram plots depict the distribution for both dependent variables and their single subtraction components. For Return Spread, in particular, it is not obvious that there is an effective lower bound of zero (Figure 1, Panel A-2). In this case, the OLS regression would deliver consistent results. The distribution of Credit Spread is also closer to symmetry than to a distribution with a bulk close to zero (Figure 1, Panel A-1), even if its minuend - the interest rate - shows a clearer limited distribution feature (Figure 1, Panel B-1). In Figure 2, the Q-Q plot for the Return Spread (Panel B) reveals fat tails on both sides, whereas the Q-Q plot for the Credit Spread (Panel A) shows a right-skewed distribution and a lower frequency of rates around the average than for a normal distribution.

$$
\begin{aligned}
& \text { >> Insert Figure } 1 \text { here. }<<< \\
& \text { >>> Insert Figure } 2 \text { here. }<<<
\end{aligned}
$$

The observations of negative values and the curvature of the probability distribution functions do not clearly point towards a truncation at the value of zero for Credit Spread and Return Spread. This is particularly true for the latter. Summarizing, a simple OLS approach seems to be reasonable for our empirical analysis. Nevertheless, as a robustness check, we now also apply a Truncated Normal Hurdle (TNH) regression so that we are able to compare these results with the previous OLS estimations.

\subsection{Truncated Normal Hurdle (TNH) Regression}

Based on the idea of Cragg (1971), the TNH regression is a two-part extension of the Type I Tobit model. The TNH approach features a separate mechanism to determine the participation decision ( $\operatorname{spread}=0$ versus spread $>0$ ) and the amount decision (magnitude of spread) 
(see Wooldridge, 2010, p. 690). In the first-step estimation, the participation equation, and in the second-step estimation, the amount equation, we use the same explanatory variables as in Table 7. Even if we see only minor differences between the results for our analysis with and without transaction costs, we adhere to the more elaborate Combined Model with transaction costs. Hence, the reference results for all further outcomes are those of Table 7 and Model (6).

In Table 9, we show the estimation results for the participation equation and the amount equation. The TNH model allows the explanatory variables to determine the participation decision and the amount decision in different ways. For example, Yield Curve decreases Credit Spread and Return Spread in the amount model but appears to have no significant effect on the participation decision. For the key variables, Credit Size-Fee and Average Investment Size, the signs are the same in both TNH model equations; Credit Size-Fee increases the participation willingness, whereas Average Investment Size decreases it. In the amount equation, both variables show almost the same attributes as in the OLS regression - a highly significant conventional magnitude effect in the case of lending and a highly significant reverse magnitude effect in the case of borrowing. Additionally, the coefficients for the non-linear effects of Credit SizeFee and Average Investment Size are comparable for both regression approaches, but in Table 9 they are not statistically different from zero at conventional levels. The amount decision's results are essentially the same between the Borrowing Model and the Combined Model, whereas the Investment Model and Combined Model are resemblant of each other in the participation decisions.

$$
\text { >> Insert Table } 9 \text { here. }<<<
$$

In Table 10, we compare the unconditional average partial effects (APEs) of the two most important factors (Credit Size-Fee and Average Investment Size) in the OLS regression setting (see Table 7) and for the TNH regression approach (see Table 9). The results for Credit Size-Fee and Average Investment Size are very similar as well in both settings in the Combined Model. The APE of Credit Size-Fee is 0.0311 (OLS) and 0.0326 (TNH), the APE of Average 
Investment Size is -0.3925 (OLS) and $-0.3806(\mathrm{TNH})$. All coefficients are statistically significant at a level of $0.1 \%$.

$$
\text { >> Insert Table } 10 \text { here. }<<<
$$

\section{Discussion of Results}

Our empirical findings for P2P lending are in line with a conventional magnitude effect for investment decisions and a reverse magnitude effect for borrowing decisions. Although it is somewhat weaker, we also find evidence for both magnitude effects exhibiting non-linear features. Keeping in mind that the average credit size is about 17 times higher than average investment amounts, the relevant regression coefficients for both magnitude effects are not as far apart as they might appear at first sight. However, our computations of economic significance reveal that the conventional magnitude effect is not only small in lab and field experiments but also in our real-life market dataset with larger investment amounts. Contrarily, the reverse magnitude effect is not only statistically significant but also comparatively large in economic terms - we deem this to be a particularly interesting new finding. From a theoretical point of view, a reverse magnitude effect for negative payments can hardly be explained by utility-oriented approaches. Only the present bias approach of Hardisty et al. (2013) supports a reverse magnitude effect for negative outcomes, but mainly for decision problems described in monetary units, i.e. in money frames and not in corresponding interest rates, i.e. in interest rate frames (see Hardisty et al., 2013, p. 359). In contrast, according to Breuer et al. (2019), opportunity-cost- and adjustment-cost-based considerations as theoretical justifications for the prevalence of a reverse magnitude effect in the case of negative outcomes are particularly relevant in an interest rate frame such as that of our empirical study. Our study thus offers (indirect) support for the practical relevance of cost-based approaches for explaining magnitude effects.

As already pointed out in the introductory section of our paper, a major advantage of our empirical approach is its reliance on real capital market data. It is thus not prone to the problems involved when only purely hypothetical decision situations are defined, such as in 
experiments, or when experiments are to be designed to imply negative payment consequences for participants (who - first and foremost - want to be compensated for their participation!) in order to examine the reverse magnitude effect. Nevertheless, there are some problems which can only be overcome by an experimental setting. First of all, as already explained, the decision problem for creditors and borrowers on the German P2P lending platform is characterized within an interest rate frame, which makes it impossible to draw conclusions on magnitude effects for a money frame. Moreover, real-life lending and borrowing are decisions under uncertainty. Although we have tried to control for risk considerations, it would certainly be better if all positive or negative consequences were risk-free. In addition, we cannot explicitly control for the issue of varying degrees of risk aversion across individuals (see also Andersen et al., 2008 , for the relevance of estimating risk preferences). If lenders exhibit a sufficiently decreasing relative risk aversion, this matter alone would imply a conventional magnitude effect. However, for borrowers, i.e. in the domain of negative payments, we should then observe a conventional magnitude effect as well, because higher relative risk aversion in the case of higher payment obligations (i.e. lower positive wealth) will lead to a lower willingness to pay interest rates. The opposite is true for increasing relative risk aversion. Our empirical findings would thus also be consistent with individuals who exhibit decreasing relative risk aversion in the domain of positive payments and increasing relative risk aversion for negative payments. We do not deem such a setting to be sufficiently convincing.

Both empirical and experimental studies have their specific weaknesses and strengths. Therefore, for a full-fledged picture, we need both, and the main aim of the paper at hand is to complement previous experimental findings by an empirical study based on actual market data.

\section{Conclusion}

We have shown first-time comprehensive empirical evidence based on real-life market data for a conventional magnitude effect in an interest rate frame for positive outcomes (i.e. required rates of return decreasing with investment volume) and a reverse magnitude effect for 
negative outcomes (i.e. acceptable interest rates increasing with credit size). Our results are in line with opportunity-cost and adjustment-cost based approaches, which seem to be of great importance when intertemporal decision problems are framed in interest rates, as is here the case.

Our findings might help to better understand prevailing magnitude effects in practical applications and might also be apt for deriving suggestions for a better designing of intertemporal decision problems, i.e. either choosing a money frame or an interest rate frame, as this may determine the resulting interest rates and their behavior as a function, e.g., of credit size. However, we leave it as a goal for future research to delve more deeply into this matter. 


\section{References}

Amemiya, T., 1985. Advanced Econometrics. $8^{\text {th }}$ edition. Cambridge, MA: Harvard University Press.

Andersen, S., Harrison, G.W., Lau, M.I., Rutström, E.E., 2008. Eliciting Risk and Time Preferences. Econometrica 76(3), 583-618.

Andersen, S., Harrison, G.W., Lau, M.I., Rutström, E.E., 2013. Discounting Behaviour and the Magnitude Effect: Evidence from a Field Experiment in Denmark. Economica 80(320), 670697.

Baker, F., Johnson, M.W., Bickel, W.K., 2003. Delay Discount in Current and Never-before Cigarette Smokers: Similarities and Differences across Commodity, Sign, and Magnitude. Journal of Abnormal Psychology 112(3), 382-392.

Benhabib, J., Bisin, A., Schotter A., 2010. Present-bias, Quasi Hyperbolic Discounting, and Fixed Costs. Games and Economic Behavior 69(2), 205-223.

Benzion, U., Rapoport, A., Yagil, J., 1989. Discount Rates Inferred from Decisions: An Experimental Study. Management Science 35(1), 270-284.

Berger, S.C., Gleisner, F., 2009. Emergence of Financial Intermediaries in Electronic Markets: The Case of Online P2P Lending. Business Research 2(1), 39-65.

Breuer, W., Soypak, K.C., Steininger, B.I., 2019. Conventional or Reverse Magnitude Effect for Negative Outcomes: A Matter of Framing, SSRN Working Paper.

Chapman, G.B., 1996. Temporal Discounting and Utility for Health and Money. Journal of Experimental Psychology: Learning, Memory, and Cognition 22(3), 771-791.

Charness, G., Gneezy, U., Kuhn, M.A., 2013. Experimental Methods: Extra-laboratory Experiments-extending the Reach of Experimental Economics. Journal of Economic Behavior \& Organization 91, 93-100.

Chen, L., Lesmond, D.A., Wei, J., 2007. Corporate Yield Spreads and Bond Liquidity. Journal of Finance 62(1), 119-149

Collin-Dufresne, P., Goldstein, R.S., Martin, J.S., 2001. The Determinants of Credit Spread Changes. Journal of Finance 56(6), 2177-2207.

Cox, J.C., Ross, S.A., 1976. The Valuation of Options for Alternative Stochastic Processes. Journal of Financial Economics 3(1-2), 145-166.

Cragg, J.G., 1971. Some Statistical Models for Limited Dependent Variables with Application to the Demand for Durable Goods. Econometrica 39(5), 829-844.

D’Agostino, R.B., Belanger, A., D’Agostino, R.B. Jr., 1990. A Suggestion for Using Powerful and Informative Tests of Normality. American Statistician 44(4), 316-321.

Dorfleitner, G., Priberny, C., Schuster, S., Stoiber, J., Weber, M., de Castro, I., Kammler, J., 2016. Description-text Related Soft Information in Peer-to-Peer Lending - Evidence from Two Leading European Platforms. Journal of Banking \& Finance 64(1), 169-187.

Estle, S.J., Green, L., Myerson, J., Holt, D.D., 2006. Differential Effects of Amount on Temporal and Probability Discounting of Gains and Losses. Memory \& Cognition 34(4), 914-928. 
Falk, A., Heckman, J.J., 2009. Lab Experiments Are a Major Source of Knowledge in the Social Sciences. Science 326(5952), 535-538.

Frederick, S., Loewenstein, G., O’Donoghue, T., 2002. Time Discounting and Time Preference: A Critical Review. Journal of Economic Literature 40(2), 351-401.

Green, L., Myerson J., McFadden E., 1997. Rate of Temporal Discounting Decreases with Amount of Reward. Memory \& Cognition 25(5), 715-723.

Hardisty, D.J., Appelt, K.C., Weber, E.U., 2013. Good or Bad, We Want it Now: Fixed-cost Present Bias for Gains and Losses Explains Magnitude Asymmetries in Intertemporal Choice. Journal of Behavioral Decision Making 268(4), 348-361.

Helwege, J., Turner, C., 1999. The Slope of the Credit Yield Curve for Speculative-grade Issuers. Journal of Finance 54(5), 1869-1884.

Kirby, K.N., Maraković, N.N., 1996. Delay-discounting Probabilistic Rewards: Rates Decrease as Amounts Increase. Psychonomic Bulletin \& Review 3(1), 100-104.

Lin, M., Prabhala, N.R., Viswanathan, S., 2013. Judging Borrowers by the Company They Keep: Friendship Networks and Information Asymmetry in Online Peer-to-Peer Lending. Management Science 59(1), 17-35.

Loewenstein, G., Prelec. D., 1992. Anomalies in Intertemporal Choice: Evidence and an Interpretation. Quarterly Journal of Economics 107(2), 573-597.

Longstaff, F.A., Schwartz, E.S., 1995. A Simple Approach to Valuing Risky Fixed and Floating Rate Debt. Journal of Finance 50(3), 789-819.

Merton, R.C., 1974. On the Pricing of Corporate Debt: The Risk Structure of Interest Rates. Journal of Finance 29(2), 449-470.

Mitchell, S.H., Wilson, V.B., 2010. The Subjective Value of Delayed and Probabilistic Outcomes: Outcome Size Matters for Gains but not for Losses. Behavioural Processes 83(1), 3640 .

Pope, D.G., Sydnor, J.R., 2011. What's in a Picture?: Evidence of Discrimination from Prosper.com. Journal of Human Resources 46(1), 53-92.

Read, D., Frederick, S., Scholten, M., 2013. DRIFT: An Analysis of Outcome Framing in Intertemporal Choice. Journal of Experimental Psychology: Learning, Memory, and Cognition 39(2), 573-588.

Samuelson, P.A., 1937. A Note on Measurement of Utility. Review of Economic Studies 4(2), 155-161.

Scholten, M., Read, D., 2010. The Psychology of Intertemporal Tradeoffs. Psychological Review 117(3), 925-944.

Thaler, R.H., 1981. Some Empirical Evidence on Dynamic Inconsistency. Economics Letters 8(3), 201-207.

Wooldridge, J.M., 2010. Econometric Analysis of Cross Section and Panel Data. $2^{\text {nd }}$ edition.

Cambridge, MA: MIT Press. 


\section{Tables}

Table 1: Definition of variables

\begin{tabular}{|c|c|}
\hline Variables & Description \\
\hline & Dependent Variables \\
\hline Credit Spread & Interest Rate minus Risk-free Rate Dependent on Maturity; in \% \\
\hline Interest Rate & Nominal interest rate of the loan; in $\%$ \\
\hline Risk-free Rate Dependent on Maturity & $\begin{array}{l}\text { Rate of return for (almost risk-free) German government bonds with } \\
\text { the respective maturity of the loan; in } \%\end{array}$ \\
\hline Return Spread & Expected Return minus Risk-free Rate Dependent on Maturity; in \% \\
\hline Expected Return & $\begin{array}{l}\text { Nominal interest rate minus investor-specific transaction costs (risk } \\
\text { surcharge and lender's fee) calculated by Smava; in \% }\end{array}$ \\
\hline & Independent Variables \\
\hline Credit Size (in EUR 1,000) & A borrower's total loan amount \\
\hline Credit Size Squared & The square of Credit Size \\
\hline Fee (in EUR 1,000) & $\begin{array}{l}\text { Transaction costs (Fee) paid by the borrower. The fee scheme had } \\
\text { changed over time. At the beginning, it was } 1 \% \text { of the Credit Size; } \\
\text { since February 2009, it was } 2 \% \text { for a Maturity of } 36 \text { months and } \\
2.5 \% \text { otherwise; since June } 2010 \text {, it was } 2.5 \% \text { for a Maturity of } 36 \\
\text { months and } 3 \% \text { otherwise. Since February } 2009 \text {, the Fee was in any } \\
\text { case at least EUR } 40 \text { for a Maturity of } 36 \text { months and EUR } 60 \text { other- } \\
\text { wise. }\end{array}$ \\
\hline Average Investment Size (in EUR 1,000) & Lenders' average amount invested in a loan \\
\hline Average Investment Size Squared & The square of Average Investment Size \\
\hline Risk-free Rate (10 Ys Treasury Yield) & $\begin{array}{l}\text { Rate of return of the 10-year German government bond; yearly re- } \\
\text { turn }\end{array}$ \\
\hline Yield Curve (10-2 Years) & $\begin{array}{l}\text { Difference between the rate of return of the } 10 \text {-year and the } 2 \text {-year } \\
\text { German government bond; yearly return }\end{array}$ \\
\hline Stock Market Returns (DAX) & Monthly return of the German stock market index DAX \\
\hline Schufa Rating & $\begin{array}{l}\text { Dummy variables for eight different categories of a borrower's credit } \\
\text { risk measured by the company Schufa; comparable with FICO Score } \\
\text { in the US or Experian, Equifax, and TransUnion in the UK: A (best) } \\
-\mathrm{H} \text { (lowest) }\end{array}$ \\
\hline KDF Indicator & $\begin{array}{l}\text { Dummy variables for four different categories of a borrower's "debt } \\
\text { service capacity" (KDF) to predict her/his funding and default proba- } \\
\text { bility: } 1 \text { (best) }-4 \text { (lowest) }\end{array}$ \\
\hline Maturity & $\begin{array}{l}\text { Dummy variable for the different credit maturities: } 36,60 \text {, and } 84 \\
\text { months }\end{array}$ \\
\hline Repeat Borrower & $\begin{array}{l}\text { Takes the value of } 1 \text { if a borrower had taken a loan more than once } \\
\text { in the sample and } 0 \text { otherwise. }\end{array}$ \\
\hline Age & Borrower's age in years \\
\hline Female & Takes the value of 1 for female borrowers and 0 otherwise. \\
\hline Investment Sample & $\begin{array}{l}\text { Takes the value of } 1 \text { for an observation related to a lender and } 0 \text { oth- } \\
\text { erwise. }\end{array}$ \\
\hline Year & Dummy variables for the years $2007-2013$; base year is 2007 \\
\hline
\end{tabular}

This table shows the definition of the variables under consideration. The credit data are collected from Smava (a German P2P platform) between February 2007 and April $2013(\mathrm{~N}=9,133)$. All capital market data are obtained from Thomson Reuters Datastream. 
Table 2: Summary statistics of dependent and independent variables

\begin{tabular}{lccccccc}
\hline & \multicolumn{5}{c}{ February 2007 - April 2013 (N =9,133) } \\
\cline { 2 - 8 } Dependent Variables & Mean & Min. & Q1 & Median & Q3 & Max. & Std. Dev. \\
\hline Credit Spread & 6.91 & -1.67 & 4.73 & 6.21 & 8.67 & 17.15 & 2.89 \\
$\quad$ Interest Rate & 8.94 & 2.20 & 6.50 & 8.20 & 10.80 & 18.00 & 3.16 \\
$\quad$ Risk-free Rate Dependent on Maturity & 2.04 & 0.08 & 1.34 & 2.01 & 2.60 & 4.50 & 1.01 \\
Return Spread & 3.79 & -6.26 & 2.84 & 3.71 & 4.69 & 12.41 & 1.71 \\
$\quad$ Expected Return & 5.83 & -4.40 & 4.60 & 5.50 & 6.90 & 15.60 & 1.94
\end{tabular}

Independent Variables

\begin{tabular}{|c|c|c|c|c|c|c|c|}
\hline Credit Size (in EUR 1,000) & 8.23 & 0.25 & 3.00 & 5.50 & 10.50 & 50.00 & 7.54 \\
\hline Fee (in EUR 1,000) & 0.21 & 0.003 & 0.06 & 0.14 & 0.30 & 1.50 & 0.22 \\
\hline Average Investment Size (in EUR 1,000) & 0.47 & 0.25 & 0.35 & 0.42 & 0.53 & 10.00 & 0.25 \\
\hline Risk-free Rate (10 Ys Treasury Yield) & 2.94 & 1.36 & 2.34 & 3.10 & 3.43 & 4.54 & 0.77 \\
\hline Yield Curve (10-2 Years) & 1.54 & -0.11 & 1.39 & 1.61 & 2.00 & 2.22 & 0.57 \\
\hline Stock Market Returns (DAX) & 0.78 & -19.19 & -2.94 & 1.32 & 3.90 & 16.76 & 6.13 \\
\hline Schufa Rating $=A$ & 0.21 & 0 & 0 & 0 & 0 & 1 & 0.41 \\
\hline Schufa Rating $=B$ & 0.19 & 0 & 0 & 0 & 0 & 1 & 0.39 \\
\hline Schufa Rating $=C$ & 0.10 & 0 & 0 & 0 & 0 & 1 & 0.30 \\
\hline Schufa Rating $=D$ & 0.10 & 0 & 0 & 0 & 0 & 1 & 0.30 \\
\hline Schufa Rating $=E$ & 0.10 & 0 & 0 & 0 & 0 & 1 & 0.30 \\
\hline Schufa Rating $=F$ & 0.10 & 0 & 0 & 0 & 0 & 1 & 0.31 \\
\hline Schufa Rating $=G$ & 0.13 & 0 & 0 & 0 & 0 & 1 & 0.34 \\
\hline Schufa Rating $=H$ & 0.08 & 0 & 0 & 0 & 0 & 1 & 0.26 \\
\hline$K D F$ Indicator $=1$ & 0.14 & 0 & 0 & 0 & 0 & 1 & 0.35 \\
\hline$K D F$ Indicator $=2$ & 0.23 & 0 & 0 & 0 & 0 & 1 & 0.42 \\
\hline$K D F$ Indicator $=3$ & 0.38 & 0 & 0 & 0 & 1 & 1 & 0.49 \\
\hline$K D F$ Indicator $=4$ & 0.24 & 0 & 0 & 0 & 0 & 1 & 0.43 \\
\hline Maturity $=36$ Months & 0.32 & 0 & 0 & 0 & 1 & 1 & 0.47 \\
\hline Maturity $=60$ Months & 0.67 & 0 & 0 & 1 & 1 & 1 & 0.47 \\
\hline Maturity $=84$ Months & 0.02 & 0 & 0 & 0 & 0 & 1 & 0.13 \\
\hline Repeat Borrower & 0.35 & 0 & 0 & 0 & 1 & 1 & 0.48 \\
\hline Age & 46.01 & 20 & 36 & 45 & 53 & 95 & 13.34 \\
\hline Female & 0.27 & 0 & 0 & 0 & 1 & 1 & 0.45 \\
\hline Year $=2007$ & 0.03 & 0 & 0 & 0 & 0 & 1 & 0.17 \\
\hline Year $=2008$ & 0.11 & 0 & 0 & 0 & 0 & 1 & 0.31 \\
\hline Year $=2009$ & 0.21 & 0 & 0 & 0 & 0 & 1 & 0.41 \\
\hline Year $=2010$ & 0.29 & 0 & 0 & 0 & 1 & 1 & 0.45 \\
\hline Year $=2011$ & 0.19 & 0 & 0 & 0 & 0 & 1 & 0.39 \\
\hline Year $=2012$ & 0.15 & 0 & 0 & 0 & 0 & 1 & 0.36 \\
\hline Year $=2013$ & 0.02 & 0 & 0 & 0 & 0 & 1 & 0.15 \\
\hline
\end{tabular}

This table presents the descriptive statistics of independent and dependent variables used in our empirical analysis. For more details regarding the definitions of the variables, see Table 1. Min. and Max. are the minimum and the maximum value of a specific variable; Q1 stands for the $25^{\text {th }}$ percentile and Q3 for the $75^{\text {th }}$ percentile; Std. Dev. stands for the standard deviation. 
Table 3: Correlation matrix (credit score dummies)

\begin{tabular}{lcccccccc}
\hline & & \multicolumn{7}{c}{ Schufa Rating } \\
& $A$ & $B$ & $C$ & $D$ & $E$ & $F$ & $G$ & $H$ \\
\cline { 2 - 9 }$K D F=1$ & $0.02^{*}$ & 0.01 & 0.01 & -0.01 & -0.02 & -0.02 & -0.01 & -0.01 \\
$K D F=2$ & $0.04^{*}$ & 0.00 & 0.01 & 0.01 & $-0.04^{*}$ & 0.00 & -0.02 & $-0.02^{*}$ \\
$K D F=3$ & $-0.04^{*}$ & 0.00 & -0.02 & -0.01 & $0.05^{*}$ & 0.01 & 0.02 & 0.01 \\
$K D F=4$ & -0.02 & -0.01 & 0.00 & 0.01 & -0.01 & 0.00 & 0.00 & $0.03^{*}$ \\
\hline
\end{tabular}

This table displays the pairwise Spearman's rank correlation coefficients between the two different credit score systems (Schufa Rating and KDF Indicator) in our sample. The Schufa Rating $(A-H)$ is based on the assessment of a German rating company, which issues ratings regarding the creditworthiness of a certain individual based on their historical records including current accounts, credit card debts, smartphone contracts, leasing contracts, loans and mail order purchases. Each individual is assigned to a category between $A$ (best) and $H$ (worst). The credit platform Smava itself calculates an individual's free net disposable income and transforms the ratio of this disposable income to the interest payments (KDF Indicator) into grades between 1 (best) and 4 (worst). The symbol * indicates a correlation coefficient's significance at the $5 \%$ level or better. 
Table 4: Correlation matrix (metric variables)

\begin{tabular}{|c|c|c|c|c|c|c|c|c|c|c|c|c|}
\hline & & $(1)$ & $(2)$ & $(3)$ & $(4)$ & $(5)$ & $(6)$ & $(7)$ & $(8)$ & $(9)$ & $(10)$ & $(11)$ \\
\hline (1) & Credit Size & 1 & & & & & & & & & & \\
\hline (2) & Average Investment Size & $0.09 *$ & 1 & & & & & & & & & \\
\hline (3) & Risk-free Rate (10 Ys Treasury Yield) & $-0.15 *$ & $0.07 *$ & 1 & & & & & & & & \\
\hline (4) & Yield Curve (10-2 Years) & $0.15^{*}$ & $0.19 *$ & $-0.31^{*}$ & 1 & & & & & & & \\
\hline$(5)$ & Stock Market Returns (DAX) & $0.02 *$ & $0.04 *$ & $-0.09 *$ & $0.18 *$ & 1 & & & & & & \\
\hline (6) & Maturity $=36$ Months & $-0.32 *$ & $-0.10^{*}$ & $0.17 *$ & $-0.30 *$ & $-0.05 *$ & 1 & & & & & \\
\hline (7) & Maturity $=60$ Months & $0.28 *$ & $0.11 *$ & $-0.10^{*}$ & $0.30 *$ & $0.04 *$ & $-0.96 *$ & 1 & & & & \\
\hline$(8)$ & Maturity $=84$ Months & $0.11 *$ & $-0.03 *$ & $-0.23 *$ & $-0.03 *$ & 0.01 & $-0.09 *$ & $-0.18 *$ & 1 & & & \\
\hline (9) & Repeat Borrower & $-0.15^{*}$ & $-0.02 *$ & $0.07 *$ & $-0.09 *$ & $-0.03 *$ & $-0.02 *$ & $0.02 *$ & -0.01 & 1 & & \\
\hline$(10)$ & Age & $0.03 *$ & $0.05 *$ & $0.09 *$ & -0.01 & -0.01 & 0.00 & 0.01 & $-0.04 *$ & $-0.04 *$ & 1 & \\
\hline (11) & Female & $-0.07 *$ & $-0.02 *$ & 0.00 & 0.00 & -0.01 & 0.00 & 0.00 & 0.00 & 0.00 & $0.10^{*}$ & 1 \\
\hline
\end{tabular}

This table displays the pairwise Bravais-Pearson correlation coefficients among all metric variables (see Table 1). The symbol * indicates a correlation coefficient's significance at the $5 \%$ level or better. 
Table 5: Magnitude effects in P2P lending without transaction cost consideration (OLS)

\begin{tabular}{|c|c|c|c|}
\hline Independent Variables & $\begin{array}{c}(1) \\
\text { Borrowing } \\
\text { Model }\end{array}$ & $\begin{array}{c}(2) \\
\text { Investment } \\
\text { Model }\end{array}$ & $\begin{array}{c}(3) \\
\text { Combined } \\
\text { Model }\end{array}$ \\
\hline Credit Size (in EUR 1,000) & $\begin{array}{c}0.0377^{* * *} \\
(6.816)\end{array}$ & & $\begin{array}{c}0.0400^{* * *} \\
(7.190)\end{array}$ \\
\hline Credit Size Squared & $\begin{array}{c}-0.0005 * * * \\
(-3.647)\end{array}$ & & $\begin{array}{c}-0.0005^{* * * *} \\
(-3.940)\end{array}$ \\
\hline Average Investment Size (in EUR 1,000) & & $\begin{array}{c}-0.3163^{* *} \\
(-2.873)\end{array}$ & $\begin{array}{c}-0.4383 * * * \\
(-3.947)\end{array}$ \\
\hline Average Investment Size Squared & & $\begin{array}{l}0.0160 \\
(1.238)\end{array}$ & $\begin{array}{c}0.0328^{*} \\
(2.527)\end{array}$ \\
\hline Risk-free Rate (10 Ys Treasury Yield) & $\begin{array}{c}-0.9599 * * * \\
(-18.925)\end{array}$ & $\begin{array}{c}-0.9384 * * * \\
(-18.422)\end{array}$ & $\begin{array}{c}-0.9453 * * * \\
(-18.616)\end{array}$ \\
\hline Yield Curve (10-2 Years) & $\begin{array}{c}-0.2554 * * * \\
(-3.467)\end{array}$ & $\begin{array}{c}-0.2182 * * \\
(-2.961)\end{array}$ & $\begin{array}{c}-0.2354^{* *} \\
(-3.209)\end{array}$ \\
\hline Stock Market Returns (DAX) & $\begin{array}{c}-0.0073^{* *} \\
(-2.590)\end{array}$ & $\begin{array}{c}-0.0079^{* *} \\
(-2.822)\end{array}$ & $\begin{array}{c}-0.0075^{* *} \\
(-2.667)\end{array}$ \\
\hline Schufa Rating & Yes & Yes & Yes \\
\hline$K D F$ & Yes & Yes & Yes \\
\hline Maturity $=60$ Months & $\begin{array}{c}-0.5705^{* * *} \\
(-11.425)\end{array}$ & $\begin{array}{c}-0.4452 * * * \\
(-9.456)\end{array}$ & $\begin{array}{c}-0.5575^{* * *} * \\
(-11.142)\end{array}$ \\
\hline Maturity $=84$ Months & $\begin{array}{c}-1.2917 * * * \\
(-11.020)\end{array}$ & $\begin{array}{c}-1.0590 * * * \\
(-9.392)\end{array}$ & $\begin{array}{c}-1.2910 * * * \\
(-10.979)\end{array}$ \\
\hline Repeat Borrower & $\begin{array}{l}0.0613 \\
(1.429)\end{array}$ & $\begin{array}{l}-0.0015 \\
(-0.036)\end{array}$ & $\begin{array}{l}0.0614 \\
(1.435)\end{array}$ \\
\hline Age & $\begin{array}{c}0.0071 * * * \\
(4.721)\end{array}$ & $\begin{array}{c}0.0076^{* * *} \\
(5.106)\end{array}$ & $\begin{array}{c}0.0073 * * * \\
(4.857)\end{array}$ \\
\hline Female & $\begin{array}{c}0.0825^{*} \\
(1.964)\end{array}$ & $\begin{array}{l}0.0538 \\
(1.281)\end{array}$ & $\begin{array}{l}0.0800 \\
(1.909)\end{array}$ \\
\hline Constant & $\begin{array}{c}14.1166^{* * *} \\
(50.432)\end{array}$ & $\begin{array}{c}14.2987 * * * \\
(50.468)\end{array}$ & $\begin{array}{c}14.2385^{* * *} \\
(50.588)\end{array}$ \\
\hline Year & Yes & Yes & Yes \\
\hline $\begin{array}{l}\text { Observations } \\
\text { Adj. } R^{2}\end{array}$ & 9,133 & $\begin{array}{l}9,133 \\
0.744\end{array}$ & $\begin{array}{c}18,266 \\
0.747\end{array}$ \\
\hline
\end{tabular}

This table presents the results for OLS regressions of Credit Spread on different independent variables. For more details regarding the definitions of the independent variables, see Table 1. Standard errors are clustered by borrower ID. Robust $t$-statistics are reported in parentheses. *** $p \leq 0.1 \%,{ }^{* *} p \leq 1 \%,{ }^{*} p \leq 5 \%$. 
Table 6: Economic significance of the conventional and the reverse magnitude effect

\begin{tabular}{|c|c|c|c|c|}
\hline \multirow[b]{3}{*}{ Maturity } & \multicolumn{4}{|c|}{$\begin{array}{c}\text { Interest payment changes (in EUR) induced by a standard deviation increase of } \\
\text { Average Investment Size or Credit Size }\end{array}$} \\
\hline & \multicolumn{2}{|c|}{ Conventional (Average Investment Size) } & \multicolumn{2}{|c|}{ Reverse (Credit Size) } \\
\hline & Mean & Median & Mean & Median \\
\hline 1 year & 0.71 & 0.66 & 32.80 & 29.91 \\
\hline 4.45 years (mean) & 3.15 & 2.96 & 145.95 & 133.10 \\
\hline 5 years (median) & 3.54 & 3.32 & 163.99 & 149.55 \\
\hline
\end{tabular}

This table shows the economic importance of the conventional and the reverse magnitude effect with respect to Average Investment Size or Credit Size for increases of a Std. Dev. and over different contract terms (1 year, mean of Maturity, and median of Maturity). The values are based on the coefficients of the Combined Model of Table 5. Std. Dev. stands for standard deviation. For more descriptive statistics of Average Investment Size, Credit Size, and Maturity, see Table 2. 
Table 7: Magnitude effects in P2P lending with transaction cost consideration (OLS)

\begin{tabular}{|c|c|c|c|}
\hline Independent Variables & $\begin{array}{c}(4) \\
\text { Borrowing } \\
\text { Model }\end{array}$ & $\begin{array}{c}(5) \\
\text { Investment } \\
\text { Model }\end{array}$ & $\begin{array}{c}(6) \\
\text { Combined } \\
\text { Model }\end{array}$ \\
\hline Credit Size-Fee (in EUR 1,000) & $\begin{array}{c}0.0388^{* * *} \\
(6.816)\end{array}$ & & $\begin{array}{c}0.0394 * * * \\
(7.004)\end{array}$ \\
\hline Credit Size-Fee Squared & $\begin{array}{c}-0.0005 * * * \\
(-3.635)\end{array}$ & & $\begin{array}{c}-0.0005^{* * *} \\
(-3.776)\end{array}$ \\
\hline Average Investment Size (in EUR 1,000) & & $\begin{array}{c}-0.2880^{* *} \\
(-2.620)\end{array}$ & $\begin{array}{c}-0.4218^{* * *} \\
(-3.807)\end{array}$ \\
\hline Average Investment Size Squared & & $\begin{array}{l}0.0131 \\
(1.021)\end{array}$ & $\begin{array}{c}0.0311^{*} \\
(2.399)\end{array}$ \\
\hline Risk-free Rate (10 Ys Treasury Yield) & $\begin{array}{c}-0.9602 * * * \\
(-18.932)\end{array}$ & $\begin{array}{c}-0.9508 * * * \\
(-18.533)\end{array}$ & $\begin{array}{c}-0.9515^{* * *} \\
(-18.692)\end{array}$ \\
\hline Yield Curve (10-2 Years) & $\begin{array}{c}-0.2554 * * * \\
(-3.468)\end{array}$ & $\begin{array}{c}-0.2169^{* *} \\
(-2.912)\end{array}$ & $\begin{array}{c}-0.2342 * * \\
(-3.180)\end{array}$ \\
\hline Stock Market Returns (DAX) & $\begin{array}{c}-0.0073^{* *} \\
(-2.588)\end{array}$ & $\begin{array}{c}-0.0078 * * \\
(-2.737)\end{array}$ & $\begin{array}{c}-0.0074 * * \\
(-2.630)\end{array}$ \\
\hline Schufa Rating & Yes & Yes & Yes \\
\hline$K D F$ & Yes & Yes & Yes \\
\hline Maturity $=60$ Months & $\begin{array}{c}-0.5702 * * * \\
(-11.424)\end{array}$ & $\begin{array}{c}0.3821 * * * \\
(8.175)\end{array}$ & $\begin{array}{c}-0.1412^{* *} \\
(-2.836)\end{array}$ \\
\hline Maturity $=84$ Months & $\begin{array}{c}-1.2916^{* * *} \\
(-11.020)\end{array}$ & $\begin{array}{c}0.2257 * \\
(2.283)\end{array}$ & $\begin{array}{c}-0.6439 * * * \\
(-5.918)\end{array}$ \\
\hline Repeat Borrower & $\begin{array}{l}0.0616 \\
(1.436)\end{array}$ & $\begin{array}{l}-0.0063 \\
(-0.149)\end{array}$ & $\begin{array}{l}0.0578 \\
(1.358)\end{array}$ \\
\hline Age & $\begin{array}{c}0.0071^{* * *} \\
(4.719)\end{array}$ & $\begin{array}{c}0.0077 * * * \\
(5.157)\end{array}$ & $\begin{array}{c}0.0073 * * * \\
(4.891)\end{array}$ \\
\hline Female & $\begin{array}{c}0.0825^{*} \\
(1.966)\end{array}$ & $\begin{array}{l}0.0479 \\
(1.148)\end{array}$ & $\begin{array}{l}0.0767 \\
(1.835)\end{array}$ \\
\hline Investment Sample & & & $\begin{array}{c}-3.1215 * * * \\
(-122.466)\end{array}$ \\
\hline Constant & $\begin{array}{c}14.1157 * * * \\
(50.431)\end{array}$ & $\begin{array}{c}5.7133 * * * \\
(20.482)\end{array}$ & $\begin{array}{c}11.5083^{* * *} \\
(41.092)\end{array}$ \\
\hline Year & Yes & Yes & Yes \\
\hline Observations & 9,133 & 9,133 & 18,266 \\
\hline Adj. $R^{2}$ & 0.746 & 0.262 & 0.612 \\
\hline
\end{tabular}

This table presents the results of OLS regressions for Credit Spread (Borrowing and Combined Model) or Return Spread (Investment or Combined Model), respectively, on different independent variables. For the Borrowing Model, Credit Size is corrected by Fee. In the Combined Model, both previous models (Borrowing and Investment) are merged. A dummy variable (Investment Sample) is included to control for a systematic difference. For more details regarding the definitions of the independent variables, see Table 1. Standard errors are clustered by borrower ID. Robust $t$-statistics are reported in parentheses. ${ }^{* * *} p \leq 0.1 \%,{ }^{* *} p \leq 1 \%, * p \leq 5 \%$. 
Table 8: Higher distribution moments of dependent variables

\begin{tabular}{lcc}
\hline & Credit Spread & Return Spread \\
\hline Skewness & 0.7408 & 0.0009 \\
Kurtosis & 2.9974 & 5.0164 \\
& & \\
Skewness and Kurtosis tests for normality & & \\
$\quad$-value (Skewness) & 0.0000 & 0.9719 \\
p-value (Kurtosis) & 0.9901 & 0.0000 \\
$\chi^{2}(2)$ & 674.26 & 429.22 \\
p-value (joint) & 0.0000 & 0.0000 \\
\hline
\end{tabular}

This table presents the $3^{\text {rd }}$ moment (Skewness) and $4^{\text {th }}$ moment (Kurtosis) of dependent variables' distribution (Credit Spread and Return Spread). The $\chi^{2}$ and $p$-values of the skewness, kurtosis, and joint tests are based on the test settings of D'Agostino et al. (1990). 
Table 9: Magnitude effects in P2P lending with transaction cost consideration (TNH)

\begin{tabular}{|c|c|c|}
\hline \multirow[b]{2}{*}{ Independent Variables } & \multicolumn{2}{|c|}{$\begin{array}{c}(7) \\
\text { Combined Model }\end{array}$} \\
\hline & Panel A: Amount & Panel B: Participation \\
\hline Credit Size-Fee (in EUR 1,000) & $\begin{array}{c}0.0293 * * * \\
(4.971)\end{array}$ & $\begin{array}{c}0.1293^{* * *} \\
(8.147)\end{array}$ \\
\hline Credit Size-Fee Squared & $\begin{array}{l}-0.0002 \\
(-1.529)\end{array}$ & $\begin{array}{c}-0.0024 * * * \\
(-7.832)\end{array}$ \\
\hline Average Investment Size (in EUR 1,000) & $\begin{array}{c}-0.3429 * * \\
(-2.951)\end{array}$ & $\begin{array}{c}-1.3899 * * * \\
(-5.132)\end{array}$ \\
\hline Average Investment Size Squared & $\begin{array}{l}0.0158 \\
(1.183)\end{array}$ & $\begin{array}{c}0.3290^{* * *} \\
(2.808)\end{array}$ \\
\hline Risk-free Rate (10 Ys Treasury Yield) & $\begin{array}{c}-1.0435^{* * *} \\
(-19.948)\end{array}$ & $\begin{array}{c}-0.6130 * * * \\
(-4.354)\end{array}$ \\
\hline Yield Curve (10-2 Years) & $\begin{array}{c}-0.2545^{* * *} \\
(-3.445)\end{array}$ & $\begin{array}{l}-0.1623 \\
(-1.124)\end{array}$ \\
\hline Stock Market Returns (DAX) & $\begin{array}{c}-0.0093 * * \\
(-3.207)\end{array}$ & $\begin{array}{l}0.0016 \\
(0.306)\end{array}$ \\
\hline Schufa Rating & Yes & Yes \\
\hline$K D F$ & Yes & Yes \\
\hline Maturity $=60$ Months & $\begin{array}{c}-0.1733 * * * \\
(-3.362)\end{array}$ & $\begin{array}{l}0.0249 \\
(0.325)\end{array}$ \\
\hline Maturity $=84$ Months & $\begin{array}{c}-0.7166^{* * *} \\
(-5.836)\end{array}$ & $\begin{array}{l}-0.4699 \\
(-0.923)\end{array}$ \\
\hline Repeat Borrower & $\begin{array}{l}0.0489 \\
(1.125)\end{array}$ & $\begin{array}{l}0.1581 \\
(1.857)\end{array}$ \\
\hline Age & $\begin{array}{c}0.0078 * * * \\
(5.098)\end{array}$ & $\begin{array}{l}0.0057 \\
(1.821)\end{array}$ \\
\hline Female & $\begin{array}{l}0.0670 \\
(1.548)\end{array}$ & $\begin{array}{l}0.1280 \\
(1.520)\end{array}$ \\
\hline Investment Sample & $\begin{array}{c}-3.3089 * * * \\
(-102.299)\end{array}$ & $\begin{array}{c}-1.6673 * * * \\
(-12.553)\end{array}$ \\
\hline Constant & $\begin{array}{c}12.6596 * * * \\
(45.281)\end{array}$ & $\begin{array}{c}4.9095 * * * \\
(7.989)\end{array}$ \\
\hline Year & Yes & Yes \\
\hline $\begin{array}{l}\hat{\sigma} \\
\text { (Standard Error) } \\
\text { Log likelihood } \\
\text { Observations }\end{array}$ & & \\
\hline
\end{tabular}

This table presents the results of Truncated Normal Hurdle (TNH) regressions for Credit Spread and Return Spread (Combined Model) on different independent variables. In the amount model in Panel A and in the participation model in Panel B, we use the same explanatory variables as in Table 7. For more details regarding the definitions of the independent variables, see Table 1. $\hat{\sigma}$ is the estimated standard error of the regression. Standard errors are clustered by borrower ID. Robust $z$-statistics are reported in parentheses. ${ }^{* * *} p \leq 0.1 \%,{ }^{* *} p \leq 1 \%,{ }^{*} p \leq 5 \%$. 
Table 10: Unconditional Average Partial Effects (APEs)

\begin{tabular}{|c|c|c|}
\hline \multirow[t]{2}{*}{ Key Independent Variables } & \multicolumn{2}{|c|}{ Average Partial Effects } \\
\hline & OLS & TNH \\
\hline Credit Size-Fee (in EUR 1,000) & $\begin{array}{c}0.0311 * * * \\
(8.624)\end{array}$ & $\begin{array}{c}0.0326^{* * *} \\
(8.689)\end{array}$ \\
\hline Average Investment Size (in EUR 1,000) & $\begin{array}{c}-0.3925 * * * \\
(-3.958)\end{array}$ & $\begin{array}{c}-0.3806^{* * * *} \\
(-4.053)\end{array}$ \\
\hline $\begin{array}{l}\text { This table compares the unconditional (ov } \\
\text { of Credit Size-Fee and Average Investme } \\
\text { (see Table 7) and the TNH regression sett } \\
\text { Model on Credit Spread and Return Spre } \\
\text { statistics (TNH) are reported in parenthes } \\
5 \% \text {. }\end{array}$ & $\begin{array}{l}\text { l) average pa } \\
z e \text { in the OL } \\
\text { (see Table } 9 \\
\text { Robust } t \text {-stat }\end{array}$ & $\begin{array}{l}\text { effects (APEs } \\
\text { ression settin } \\
\text { the Combined } \\
\text { (OLS) and } z\end{array}$ \\
\hline
\end{tabular}




\section{Figures}

Figure 1: Histogram of dependent variables (Credit Spread and Return Spread) and their individual subtraction components
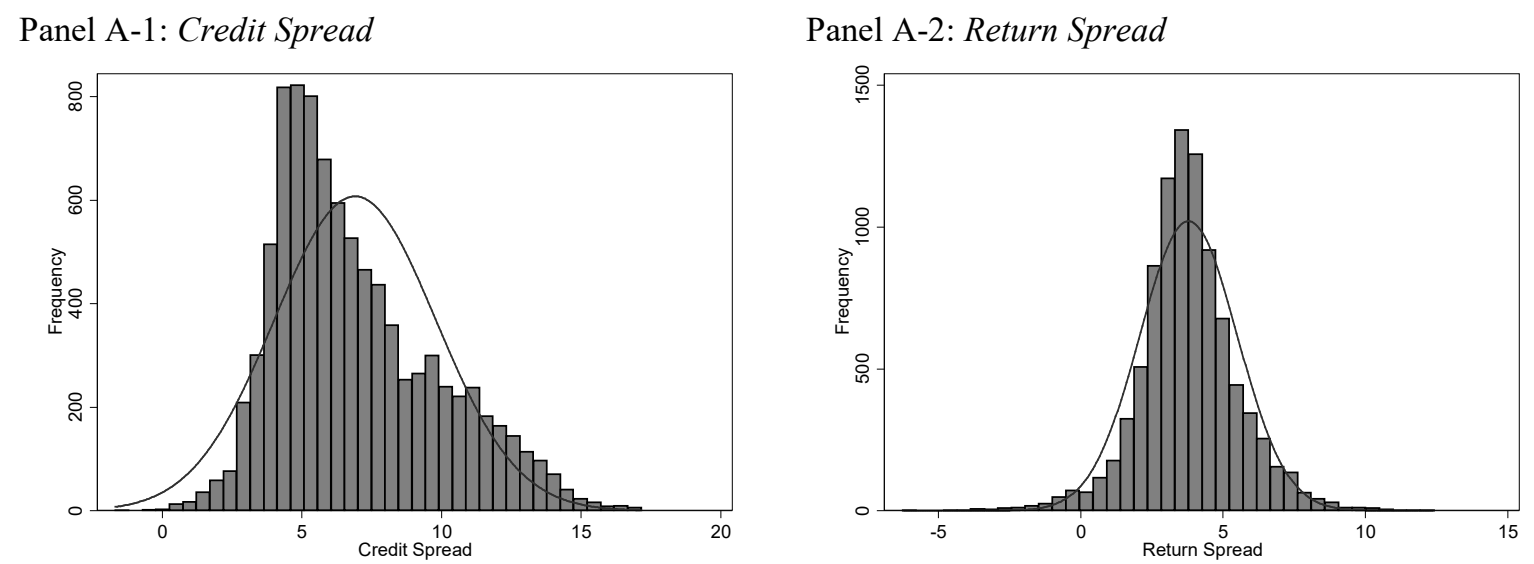

Panel B-1: Interest Rate - first component

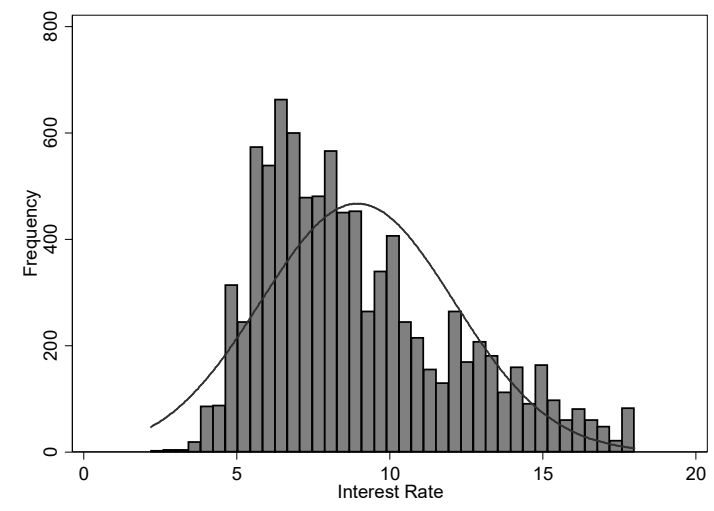

Panel B-2: Expected return - first component

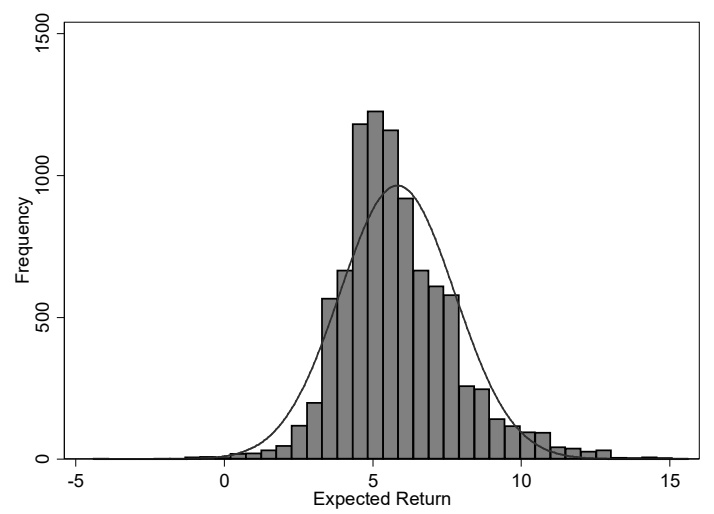

Panel C: Risk-free rate of respective German governmental bond maturity - second component

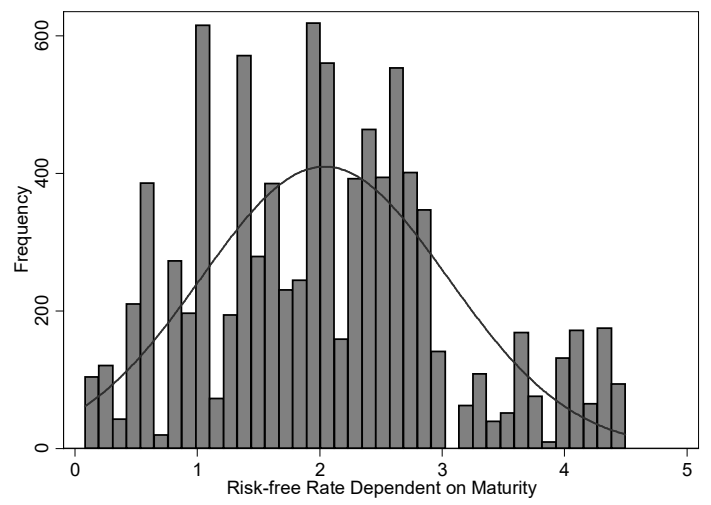

This figure shows the histogram plots of our different dependent variables and their individual subtraction components with their frequencies and an overlaid normal density curve. The frequency numbers on the vertical axis are in absolute values; the numbers on the horizontal axis are in percentage points. The dependent variable Credit Spread is shown in Panel A-1, its first subtraction component, the nominal interest rate of the loan, in Panel B-1, and its second component, the risk-free interest rate, in Panel C. The dependent variable Return Spread is in Panel A-2, its first component, the expected rate of return, in Panel B-2, and its second component, the risk-free interest rate, also in Panel C. 
Figure 2: Q-Q plots of dependent variables (Credit Spread and Return Spread)

Panel A

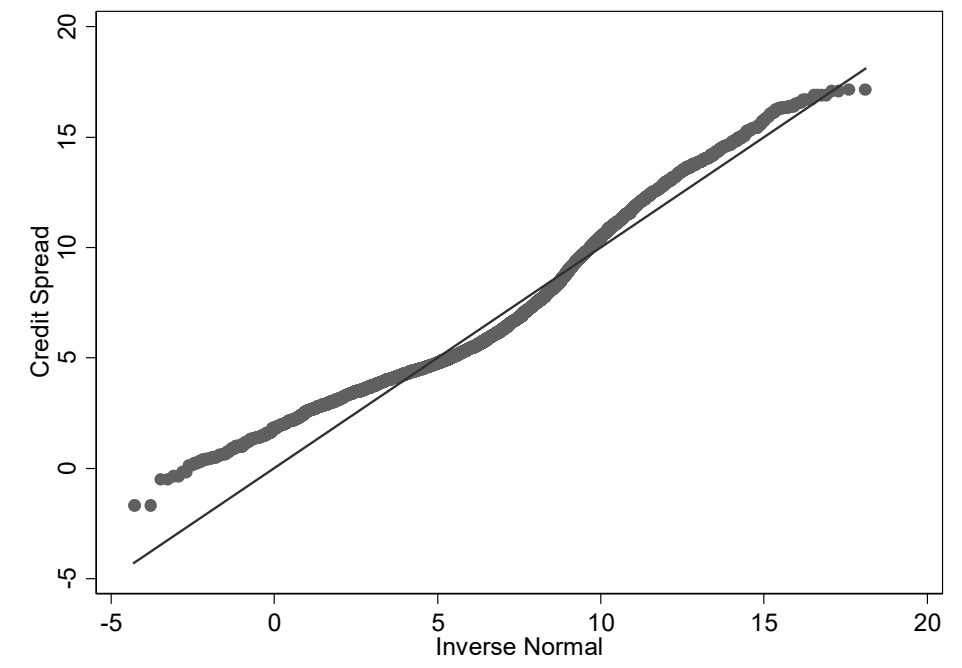

Panel B

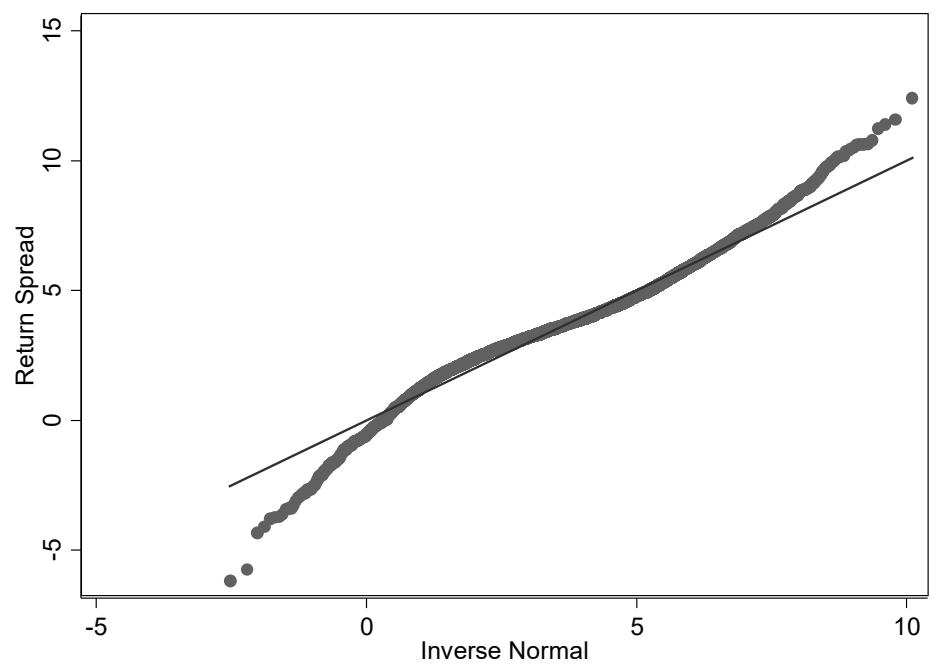

This figure shows a plot of the quantiles of the dependent variables Credit Spread (Panel A) and Return Spread (Panel B) against the quantiles of the normal distribution. Numbers on both axes are in percentage points. 